\title{
Ecoética y crisis ecológica. La perspectiva de Aldo Leopold
}

\author{
Lizbeth Sagols Salles \\ Universidad Nacional Autónoma de México \\ Lizbeth.sagols@gmail.com
}

La crisis ecológica se impone día a día. Su manifestación más evidente es el cambio climático: el aumento de calor en la atmósfera, que ha sido de $0.74 \%$ desde el inicio de la Revolución Industrial hasta nuestros días, y es consecuencia de la acumulación atmosférica de $\mathrm{CO}_{2}$ y otros gases que producen el llamado «efecto invernadero» ${ }^{1}$. El calentamiento global ha traído consigo el deshielo de los glaciares marinos y terrestres, la acidificación de los océanos que mata a especies marinas, y el aumento del nivel del mar que amenaza con desaparecer islas y ciudades costeras. Además, ha provocado gran cantidad de inundaciones, sequías severas, intensas olas de calor, huracanes, aumento brutal de incendios forestales y una acelerada extinción de especies animales y vegetales: terrestres, marinas y aéreas. Y junto con todo esto, que se agoten los recursos no renovables (minerales y combustibles fósiles) y

1 www.nationalgeographic.es/eloceano. 
los supuestamente renovables: el agua, los bosques, el aire limpio, el suelo fértil, los mares salinos.

Todo se debe al uso excesivo que hacemos de los recursos de la Tierra. Nos creemos sus dueños y los seres más importantes, con derecho a devastarla para satisfacer nuestras necesidades. Hemos ignorado por completo las necesidades de los otros seres vivos. Como bien dijo el historiador Lynn White (1967), la causa de la crisis ecológica está en nuestra cultura antropocentrista abusiva: nos hemos considerado el centro único y supremo, la especie más importante, con derecho ilimitado a reproducirnos y disponer de todos los recursos terrestres.

Es urgente contar con una ética ecológica, con una valoración radical del conjunto de los seres vivos, como la que estuvo presente durante todo el Neolítico y ha perdurado en sabidurías tradicionales como el Tao, el budismo, en San Francisco de Asís, en varias tendencias filosóficas del Renacimiento (Villoro, 1992) y en el pensamiento de Albert Schweitzer (1935). O sea, hay que recuperar las visiones holistas de la vida, pues estamos insertos en el gran todo de lo vivo.

En 1927, el teólogo protestante Fritz Jahr hizo un llamado a respetar a los animales y a todo ser vivo, y le dio a esta concepción el nombre de «bioética». No era sólo el hombre el que entraba en el ámbito de la valoración, había que incluir a todos los vivientes. Y con mayor precisión, en 1948, Aldo Leopold dedicó, al final de su libro Almanaque del condado arenoso, un capítulo titulado: «Ética de la Tierra», en el que planteó una visión integradora que otorga valor no sólo a hombres, animales y plantas, sino a todo aquéllo que contribuya a la vida: aire, rocas, tierra, agua, etcétera, y que conforme a los ecosistemas particulares, así como al gran ecosistema de la Tierra. De esta forma surge la auténtica ecoética. 
Leopold, quien era ingeniero silvicultor y profesor universitario, combinó sus inquietudes científico-naturalistas con sus aspiraciones éticas. Partió de la convicción de que la naturaleza es fuente de perfeccionamiento humano: el lugar donde buscamos y acabamos por encontrar nuestra parte divina (2000: 38); a la vez, tenía la convicción de que a lo largo de la historia ha existido una evolución ética que consiste en la ampliación histórico-progresiva de la idea de igualdad de derechos. Tal ampliación ha consistido en pasar de la inclusión de los varones, a la admisión de las mujeres (que según él se dio en Grecia -lo cual es cuestionable-) y que más tarde incluyó a los esclavos y a la sociedad en general, hasta llegar a integrar a lo no humano, a todos los seres vivos y al planeta mismo: suelo, aguas, animales y plantas o colectivamente a la Tierra. Todos estos seres son iguales y tienen el mismo derecho a la sobrevivencia, pues forman, junto con nosotros, la comunidad biótica: todos estamos interrelacionados y contribuimos a que siga vivo el gran conjunto de la vida y sus funciones. Todos los organismos que contribuimos a la vida, grandes y pequeños, tenemos derecho a sobrevivir, poseemos un valor básico y originario en tanto dependemos unos de otros, formamos simbiosis de cooperación y somos compañeros-miembros dentro de la comunidad. Hay entonces una «igualdad básica de valor» de todos los vivientes.

Por tanto, el humano no sobrevive sin el resto de los seres vivos. Los humanos no somos autosuficientes por nuestra razón, como ha creído la tradición filosófica e incluso la religiosa, sino que somos seres relativos, insuficientes y necesitados, estamos en íntima relación con la totalidad de elementos que hacen posible la vida: el clima, la tierra, los ecosistemas, etc. En pocas palabras, los recursos naturales nos conforman y permiten o entorpecen nuestros proyectos 
(Leopold, 2000: 136-37). El homo sapiens tiene que abandonar la soberbia de pensarse como un ser exclusivamente racional, ha de ser humilde, verse también como un ser que vive igual que los otros, que es sensible, material y está en íntima relación con el conjunto. No podemos pensar el valor ético de la existencia sólo en relación con los humanos, los demás seres también encarnan un valor ético: su existencia es valiosa porque gracias a las interconexiones con el resto de los vivientes mantienen y enriquecen la vida. Aunque Leopold no utilice el concepto de no antropocentrismo, es obvio que para él no podemos ser antropocéntricos.

Con base en esta idea holista de la vida y relativista sobre el ser humano, Leopold formula una propuesta literalmente ecoética muy concisa que hoy, más que nunca, es digna de consideración, no sólo por la crisis ecológica que enfrentamos, sino también porque se trata de una ecoética moderada que trasciende los problemas de las ecoéticas radicales, de modo que abre un camino teórico para reflexionar nuestros problemas ambientales.

Leopold es consciente de que estamos destruyendo la maravilla de la vida y perdiendo el sentido de reverencia y agradecimiento ante ella por el hecho de concederle importancia exclusiva a nuestra especie y concentrarnos en intereses económicos, conquistadores de los recursos naturales. La crisis ecológica - para él- consiste en estar imposibilitando el equilibrio del planeta al interrumpir el «flujo de energía vital» dentro de la «pirámide biótica». Esta última es una idea-imagen que representa una ordenación de las distintas especies, según la cadena trófica. La convivencia entre los vivientes se da entre predadores y presas y las especies del último nivel -en la cúspide de la pirámide- que se alimentan de las especies colocadas en los niveles más bajos. Los hu- 
manos se alimentan de mamíferos superiores, inferiores, de peces y vertebrados, y éstos de insectos y plantas, los cuales se nutren directamente del suelo. La condición indispensable para que fluya la energía de un nivel al otro y se mantenga la Tierra en equilibrio reside en mantener el número de ejemplares de las especies de cada nivel. Los inferiores (suelo, insectos, plantas) son abundantes en número, pero mientras más se sube, los ejemplares han de ser menos para poder seguir alimentándose de los niveles inferiores; si rebasan su número, la comida será insuficiente.

No obstante, la pirámide se ha invertido. El nivel superior -habitado por humanos- ha crecido en un número exagerado y está forzando a animales, plantas y suelo para que sigan produciendo alimentos para la población humana. Se ha ejercido violencia sobre la Tierra al sobrepoblarla y, junto con esto, en producir cambios con una velocidad extraordinaria debido al desarrollo de múltiples actividades de transformación, entre las que destacan: el traslado global de especies (animales y vegetales) endógenas de una región a otra y que muchas veces se convierten en plagas; el traslado de alimentos mediante vehículos que contaminan los caminos y alteran el aire, las rocas y los nutrientes que proporcionan los minerales; el desarrollo de una agricultura exagerada y cultivo de especies extranjeras que empobrecen la fertilidad del suelo; el uso de materias tóxicas por parte de la industria que contamina las aguas y el suelo; el intento de acabar con las especies predadoras sin advertir que son útiles para la renovación del conjunto de los ecosistemas; y el traslado de especies domesticadas de otras tierras para sustituir a las salvajes, a las que se les envía a otros hábitats (Leopold, 2000: 147-48).

El resultado de todo lo anterior ha sido la enfermedad de la Tierra, dice Leopold, y ello significa que ya no pue- 
de renovarse a sí misma (2000: 151). ¿Dónde está la causa de tal enfermedad? No hay una sola, contribuyen tanto el capitalismo devorador que, con su actitud de propietario y conquistador de la naturaleza se adueña de ella para venderla y transformarla, como la tecnología contemporánea que es altamente contaminante $y$, sin lugar a dudas, coopera la sobrepoblación, a la cual Leopold coloca en el centro. La crisis ecológica es multicausal, pero esto no elimina el hecho de que una causa pueda tener más motivos que las otras. En opinión del autor de la Ética de la Tierra, estamos rebasando la «capacidad de carga de la Tierra» con una población en extremo densa y el costo está siendo altísimo. A mayor densidad, menor crecimiento de la fertilidad y salud del planeta (2000: 151).

¿Qué ética proponer ante esta situación crítica? Nos enfrentamos aquí a dos problemas capitales, uno práctico y uno teórico de gran importancia. En el primero, si hemos llegado a tal desgaste, la tentación en la que caen muchas posturas ecoéticas es proponer la reducción al mínimo el uso de los recursos naturales, negar la cultura que hemos creado, negar nuestra condición de predadores para recuperar la naturaleza. Ésta es una postura extrema y radical. Por ejemplo, Albert Schweitzer pensaba que comer un insecto es agredir a la naturaleza. De igual forma piensan quienes proponen con pretensión de universalidad el cero uso del automóvil, el vegetarianismo o el veganismo. Las ecoéticas radicales plantean una ética de la austeridad extrema. Por el contrario, la ecoética de Leopold es «moderada», en la medida en que está consciente de que somos predadores, que hemos de alimentarnos de las especies inferiores y que, en consecuencia, el mal no está en hacer uso de la naturaleza, sino en el extremo al que hemos llegado -que nos hace devastar en vez de usar- 
debido a la sobrepoblación. Para él, lo importante es administrar mejor nuestros recursos, llevar una gestión racional y proporcionada de los ecosistemas.

Una ética de la tierra, por supuesto, no puede impedir la alteración, la gestión y el uso de los recursos, pero afirma su derecho a seguir existiendo $y$, al menos en algunos puntos, a continuar existiendo en estado natural (Leopold, 2000: 136).

Es este exceso el que urge corregir. Leopold no lo dice abiertamente, pero en tanto piensa que compartimos la Tierra con otras especies que son nuestros «compañeros-miembros», está presente en sus reflexiones la idea de que es necesario planificar el número de nacimientos futuros para que nuestra especie no predomine sobre todas las demás, de lo contrario, no estamos respetando el derecho a la sobrevivencia de otros animales y plantas.

Por otra parte, el problema teórico que plantea toda ecoética reside en la tradición imperante en la cultura occidental, la ética es asunto entre humanos y para humanos: seres axiológicamente autónomos, es decir, que elaboran su propios valores, deberes, normas y leyes para convivir con seres racionales, dotados de lenguaje, responsables y con capacidad de reciprocidad. ¿Cómo incluir, entonces, a la naturaleza que no elabora valores, no es racional, no habla, no es responsable ni recíproca con los humanos? Al parecer, se trata de dos órdenes irreconciliables entre sí. La naturaleza se presenta como la otredad radical y, en esta medida, es ajena a la ética. Las ecoéticas radicales intentan resolverlo advirtiendo valores y leyes dadas en la naturaleza, ésta no genera valores porque ya los posee, le han sido dados en su propia constitución, por lo tanto, el humano ha de subordinarse a las leyes naturales. Tal es el caso de la ecoética de Holmes Rolston III, quien piensa que los valores han sido creados por el proceso 
de evolución de las especies y a nosotros sólo nos toca reconocerlos. Por lo anterior, el humano ha de subordinar sus necesidades a las de las otras especies. Por ejemplo, entre la sobrevivencia de los rinocerontes en peligro de extinción de Zimbabue o de los niños de este país, para él es evidente que hemos de optar sin más por los rinocerontes, y que se mueran los niños de hambre, pues las otras especies tienen que vivir y nosotros hemos de reconocer ese supremo valor. Sobra decir que se trata de un extremo.

A diferencia de esta postura, Leopold incluye a la naturaleza en la ética sin subordinar; al sujeto, en las leyes del mundo natural; él transforma de raíz la concepción tradicional del sujeto a fin de que éste, sin dejar su propia condición de autonomía axiológica, creadora de sus propios valores, advierta que al mismo tiempo la naturaleza forma parte de él, puesto que es ella la que le permite sobrevivir y desarrollar la cultura. Podemos decir que para Leopold la naturaleza es otredad, es algo distinto al sujeto creador de leyes, pero a la vez, no le es ajena a éste, ambos están en íntima relación. El humano no ha de subordinarse a la naturaleza, ambos deben prosperar, hay que buscar la mejor administración de los recursos para que esto sea posible. Digamos que debemos encontrar la forma en que niños y rinocerontes sobrevivan. El pensamiento, la deliberación y el conocimiento de los ecosistemas se vuelven centrales en la ecoética de Leopold.

No se trata de una ética racionalista, por el contrario se basa al mismo tiempo en la razón y la emoción o en una racionalidad que reconoce sus raíces emotivas y en una emoción, en un sentir que sabe servirse de la razón para lograr sus mejores deseos. El fundamento de la ecoética leopoldiana es un sujeto integral capaz de entendimiento racional y de estar activo en sus capacidades espirituales, pues, como vimos al 
inicio de estas reflexiones, la naturaleza nos permite desarrollar el espíritu: «Solo alcanzamos una ética en relación con algo que podamos ver, [admirar] sentir, entender, amar, algo en lo que tengamos fe en alguna forma» (Leopold, 2000: 145). Y a partir de este fundamento, Leopold centra su ética en un cambio de disposición del sujeto, « [Una] ética de la Tierra cambia el rol del Homo Sapiens desde conquistador de la comunidad a simple miembro y ciudadano de ella. Esto implica un respeto por los otros miembros de la comunidad y también un respeto de la comunidad como tal» (2000: 136). Nada se logra en esta ética sin un cambio radical en el sujeto, incluso el deber deja de ser algo impuesto por la razón y exige una transformación, una conversión de nosotros mismos. «Las obligaciones no significan nada sin la conciencia [...] Ningún cambio ético importante se ha llevado a cabo sin un cambio interno en nuestros intereses intelectuales, lealtades, afectos y convicciones» (Leopold, 2000: 161). Es preciso, entonces, convertirnos al conocimiento y al amor a la Tierra, saber que estamos rodeados de otras especies que son nuestras compañeras en la aventura de la vida y que merecen el mismo respeto que los humanos.

Así, el bien de esta ética no es algo ideal y abstracto, ni tampoco la mera felicidad humana, ya sea comunitaria o individual, sino el cuidado del conjunto de lo vivo: «Algo es correcto cuando tiende a preservar la integridad, estabilidad y belleza de la comunidad biótica. Es incorrecto cuando tiende a lo contrario» (Leopold, 2000: 155). El logro de este bien exige actitudes muy concretas que sólo se dan si somos capaces de la conversión de que hemos hablado: deliberación cuidadosa sobre el uso de los ecosistemas buscando cooperar con las otras especies, admiración y disfrute de la Tierra como fuente de vida, y capacidad de sacrificio: no continuar 
con la explotación de los recursos naturales y, desde luego, poner límites a los nacimientos.

Finalmente, Leopold consideró que para que se extienda esta ética es necesario que la filosofía y la religión, debido a su poder de influir en las conciencias, tomen en sus manos una misión ecológica. La filosofía está haciendo su parte con los desarrollos de la ecoética y de la ética ambiental y no sólo a nivel teórico, sino que cada vez hay más cursos de ética filosófica al respecto. En las religiones hemos visto que hasta hace muy poco, las más difundidas habían sido ajenas a los problemas ecológicos, pues han sido marcadamente antropocéntricas. La única vida sagrada para ellas ha sido la vida humana y no han tenido en general (salvo excepciones como la de San Francisco y sus seguidores) una mirada para las otras formas de vida. Recientemente, llama la atención que tanto el catolicismo como el islam se han pronunciado nítida y rotundamente por la defensa de las otras formas de vida y los ecosistemas. El catolicismo, mediante la encíclica del papa Francisco I: Laudato Sí (marzo 2015) y el islam con su Declaración islámica sobre el cambio climático (agosto 2015). Así pues, se abre un horizonte prometedor -avizorado por Leopold-en el que conviene que religiosos, creyentes y laicos trabajemos juntos en pro de la vida.

\section{Bibliografía}

Leopold, A. (2000). Una ética de la Tierra. Almanaque de un condado arenoso, Jorge Riechmenn (trad). Madrid: Catarata. Schweitzer, A. (1935), Indian Thought and Its Development. (Die Weltanschanung der indischen Denker: Mystik und Ethik). Munich: C.H. Beck. 
Villoro, L. (1992). El pensamiento moderno. Filosofía del Renacimiento. México: FCE/El Colegio Nacional.

White, L. (1967). «The Historical Roots of Our Ecological Crisis», Science 115, 3767.

Fuentes electrónicas

www.nationalgeographic.es/eloceano 


\section{Resumen}

La crisis ecológica se nos impone día a día. Su manifestación más evidente es el cambio climático; por ello, se hace urgente contar con una ética ecológica con una valoración radical del conjunto de los seres vivos, como la que estuvo presente durante todo el neolítico, y que ha perdurado en sabidurías tradicionales. Con base en esta idea holista de la vida y relativista sobre el ser humano, Leopold formula una propuesta literalmente eco-ética muy concisa que hoy, más que nunca, es digna de consideración, no sólo por la crisis ecológica que enfrentamos, sino también porque se trata de una «ecoética moderada» que trasciende los problemas de las ecoéticas radicales, de modo que abre un camino teórico para pensar nuestros problemas ambientales.

Palabras clave: Aldo Leopold, ecoética, crisis ecológica.

\section{Abstract}

The ecological crisis is imposed on us day by day. The most obvious manifestation of it is climate change; therefore, it is urgent to have an ecological ethic, with a radical assessment of all living beings such as the one that was present throughout the Neolithic and that has endured in traditional wisdom. Based on this holistic idea of life and relativistic about the human being, Leopold formulates a very concise eco-ethical proposal that today, more than ever, is worthy of consideration, not only because of the ecological crisis that we face, but also because it is a «moderate eco- ethics» that transcends the problems of radical eco-ethics, so that it opens a theoretical path for thinking about our environmental problems.

Key words: Aldo Leopold, ecoethics, ecological crisis. 